\title{
ANÁLISE DA ADEQUAÇÃO DOS MUNICÍPIOS ÀS NORMAS BRASILEIRAS DE CONTABILIDADE APLICADAS AO SETOR PÚBLICO
} ADEQUATION ANALYSIS OF THE MUNICIPALITIES TO BRAZILIAN ACCOUNTING STANDARDS APPLIED TO PUBLIC SECTOR Mariangela Ravanello ${ }^{1}$ Juliana Luisa Marcuzzo ${ }^{1}$ Márcia Rosane Frey ${ }^{1}$

Recebido em: 10/06/2014 Aceito em: 10/11/2015

mfrey@unisc.br
Resumo: As Normas Brasileiras de Contabilidade Aplicadas ao Setor Público constituem o novo modelo de gestão de recursos públicos, reforçando dispositivos contidos na Lei $\mathrm{n}$. 4.320/1964 e na Lei Complementar n. 101/2000. Para os pequenos municípios, a adoção do novo padrão constitui-se num grande desafio. Nesse contexto, o estudo teve por objetivo analisar o processo de adequação dos municípios da Região Centro-Serra do Estado do Rio Grande do Sul - RS às mudanças da contabilidade aplicada ao setor público. Os resultados apontaram que os profissionais da área contábil ainda possuem pouco conhecimento em relação à complexidade das mudanças e que a aplicação dos novos procedimentos ainda não está sendo realizada. A estrutura organizacional na grande parte dos municípios analisados, no que se refere aos sistemas informatizados e fluxo de informações, não está preparada para atender às exigências das novas normas, ficando evidenciada a carência de profissionais capacitados.

Palavras-chave: Normas Brasileiras de Contabilidade Aplicadas ao Setor Público. Setor público. Harmonização contábil.

Abstract: The Brazilian Accounting Standards Applied to the Public Sector are the new model of public resource management, reinforcing devices contained in the Law n. 4.320/1.964 and Complementary Law n.101/2000. For small municipalities, the adoption of the new accounting standard constitutes a major challenge. In this context, the study aimed to analyze the process of adapting the municipalities from the region Centro - Serra of the state of Rio Grande do Sul to changes accounting applied to the public sector. The results of the study showed that accounting professionals still have little knowledge about the complexity of the changes and the implementation of the new procedures is not being performed. The organizational structure in most municipalities analyzed in relation to computerized systems and information flow, is not prepared to meet the requirements of the new standards, being evidenced the lack of trained professionals.

Keywords: Brazilian Accounting Standards Applied to the Public Sector. Public sector. Accounting harmonization.

\footnotetext{
${ }^{1}$ Universidade de Santa Cruz do Sul - UNISC - Santa Cruz do Sul - Rio Grande do Sul - Brasil.
} 


\section{INTRODUÇÃO}

O modelo da contabilidade aplicada ao setor público está alicerçado basicamente em duas Leis. A primeira e mais antiga, considerada a identidade da contabilidade pública, a Lei n. 4.320/64, estabelece regras para elaboração e controle dos orçamentos e balanços a todas as esferas de governo. Posteriormente, a Lei n. 101/200, também chamada de Lei de Responsabilidade Fiscal, estabeleceu normas de finanças públicas voltadas à gestão fiscal, representando um grande avanço no controle das contas públicas.

Com o processo de convergência da contabilidade brasileira aos padrões internacionais, a contabilidade aplicada ao setor público recebeu um novo padrão de entendimento com a edição por parte do Conselho Federal de Contabilidade, no final de 2008, das dez primeiras Normas Brasileiras de Contabilidade Aplicadas ao Setor Público, identificadas com a nomenclatura NBC T 16.1 a 16.10. Em 2011 foi instituída a décima primeira norma, a NBC T 16.11.

O conjunto dessas 11 normas constitui um novo modelo de contabilidade para o setor público. Conforme salientado por Paulo Henrique Feijó no I Seminário Internacional de Contabilidade Pública, representa um novo modelo tecnológico de recursos públicos, alicerçado aos princípios contábeis garantindo a integridade da informação no ciclo da gestão, desde o planejamento, o orçamento, a gestão financeira, até o controle. Comparativamente, em relação ao Brasil, Feijó (2007) cita, como exemplo, as experiências dos países Europeus que estão um pouco mais avançados que o Brasil, trabalhando a receita sob os dois enfoques, tanto o orçamentário quanto o patrimonial, destacando esse último como um dos importantes passos da convergência no Brasil.

As Normas Brasileiras de Contabilidade Aplicadas ao Setor Público (NBCASP), identificadas pela sigla NBC TSP, reforçaram dispositivos contidos na Lei n. 4.320/64, referente à eficácia e à efetividade, especialmente aos seus objetivos de promover a integração entre os planos, a implantação do sistema de custos e do regime de competência para as receitas. A Lei Complementar 101/00 também foi reforçada no que se refere à evidenciação da transparência e da responsabilidade da gestão fiscal. Além disso, as NBC TSP buscam migrar a cultura contábil orçamentária existente no setor público brasileiro para uma cultura contábil patrimonial.

Para o setor público, principalmente para os pequenos municípios, que representam a grande parte dos municípios brasileiros, a adoção do novo padrão de contabilidade aplicada ao setor público constitui-se num grande desafio, tendo em vista principalmente a carência de profissionais preparados e a precariedade da estrutura organizacional. Conforme estabeleceu a Portaria STN n. $828 / 11$, as novas normas de contabilidade devem ser implantadas de forma gradual até 2014 , sendo até o final de 2012 de forma facultativa e após, em 2013 a 2014, obrigatoriamente, conforme cronograma elaborado pelos municípios.

Nesse contexto de adequação dos municípios frente às mudanças na contabilidade pública decorrentes do processo de convergência, buscou-se responder ao seguinte questionamento: Como está o processo de adaptação dos Municípios da Região Centro-Serra do Estado do Rio Grande do Sul - RS, no início de 2012, em relação às mudanças da contabilidade aplicada ao setor público 
introduzidas a partir da edição das NBC TSP, sob o ponto de vista da preparação dos profissionais contábeis, da aplicação das novas normas e da estrutura organizacional dos municípios?

Buscando resposta ao questionamento, o presente estudo verificou e analisou o processo de adaptação dos Municípios da Região Centro-Serra - RS às mudanças da contabilidade no contexto da harmonização das normas de contabilidade aplicadas ao setor público sob o ponto de vista da preparação dos profissionais contábeis, da aplicação das novas normas e da estrutura organizacional dos municípios.

Como procedimento de levantamento de dados realizou-se inicialmente uma pesquisa bibliográfica no qual foram identificadas as principais mudanças para a contabilidade pública, decorrentes das NBC TSP e do processo de convergências às normas internacionais. Para a coleta dos dados empíricos junto aos municípios da Região Centro Serra - RS, composta por onze municípios, utilizou-se a pesquisa de levantamento (survey) com aplicação de um questionário aos profissionais contábeis de cada prefeitura. Em média trabalham de três a quatro servidores no setor contábil, tendo entre eles, apenas um contabilista responsável que respondeu o questionário.

Para a estruturação do presente artigo, apresenta-se inicialmente o embasamento teórico sobre os principais marcos normativos da contabilidade do setor público, bem como uma síntese das contribuições das Normas Brasileiras de Contabilidade Aplicadas ao Setor Público no processo de convergência aos padrões internacionais. Na sequência, encontra-se o detalhamento da metodologia, a análise dos dados e resultados do estudo realizado na região Centro Serra - RS e as conclusões.

\section{REFERENCIAL TEÓRICO}

Para fundamentar o presente estudo, aborda-se como referencial teórico as principais normas que regem a contabilidade pública, entendidas como marcos normativos, e as alterações mais significativas para a contabilidade aplicada ao setor público, introduzidas pelas NBC TSP, publicadas pelo Conselho Federal de Contabilidade.

\subsection{Marcos Normativos da Contabilidade Pública no Brasil}

No Brasil, o marco inicial da contabilidade pública é a Lei n. 4.320/64, que instituiu normas gerais de direito financeiro para elaboração e controle dos orçamentos e balanços da União, dos Estados, do Distrito Federal e dos Municípios.

Para Rosa (2011), a Lei 4.320/64 é a identidade da contabilidade governamental, recepcionando artigos da Constituição Federal relativos ao controle de gastos, ao patrimônio e à contabilidade pública. A referida lei está estruturada em onze títulos, sendo do I ao VIII sobre a lei, a proposta e o controle da execução orçamentária; O IX sobre a contabilidade; o X relativo às autarquias e outras entidades, e o último, $\mathrm{XI}$, as disposições finais.

Os Art. 85 e 89 dessa Lei resumem como deve ser a organização dos serviços da contabilidade pública, os quais hoje são ressaltados por meio de novas Resoluções do CFC e direcionando aos padrões internacionais:

Estudos do CEPE [ISSN 1982-6729]. Santa Cruz do Sul, n. 42, p. 114-131, jul./dez. 2015. 
Os serviços de contabilidade serão organizados de forma a permitirem o acompanhamento da execução orçamentária, o conhecimento da composição patrimonial, a determinação dos custos dos serviços industriais, o levantamento dos balanços gerais, a análise e a interpretação dos resultados econômicos e financeiros. [...] A contabilidade evidenciará os fatos ligados à administração orçamentária, financeira, patrimonial e industrial (BRASIL, Lei n. 4.320/64).

Em 2000, houve um avanço significativo para o setor público, envolvendo a contabilidade, com a Lei n. 101/00, também chamada Lei de Responsabilidade Fiscal, que estabeleceu normas de finanças públicas voltadas para a responsabilidade e transparência na gestão fiscal. Com esta lei foram introduzidos novos conceitos à administração pública, focados no planejamento, na transparência, no controle, na responsabilidade e consolidação das normas e regras contidas em dispositivos constitucionais, como limites a serem observados para as principais variáveis e metas fiscais.

Em seu artigo $1^{\circ}, \S 1^{\circ}$ a Lei de Responsabilidade Fiscal assim dispõe:

\begin{abstract}
A responsabilidade na gestão fiscal pressupõe a ação planejada e transparente, em que se previnem riscos e corrigem desvios capazes de afetar o equilíbrio das contas públicas, mediante o cumprimento de metas de resultados entre receitas e despesas e a obediência a limites e condições no que tange a renúncia de receita, geração de despesas com pessoal, da seguridade social e outras, dívidas consolidada e mobiliária, operações de crédito, inclusive por antecipação de receita, concessão de garantia e inscrição em Restos a Pagar (BRASIL, Lei. n. 101/00).
\end{abstract}

Pode-se dizer que, enquanto a Lei n. 4.320/64 preocupou-se em instituir regras para elaboração e controle dos orçamentos e balanços, a Lei n. 101/00 buscou instituir regras incluindo o atingimento de metas e o cumprimento de limites legais, visando a uma gestão fiscal responsável traduzida no equilíbrio das contas públicas, na preservação do patrimônio público e na transparência das ações governamentais.

Essas duas legislações trouxeram vários dispositivos sobre a contabilidade. No entanto, como voltaram mais suas regulamentações para o orçamento, envolvendo a receita e a despesa pública, a contabilidade governamental continuou sendo executada sob a perspectiva do orçamento.

Dentro do processo de convergência aos padrões internacionais que a contabilidade vem sofrendo nos últimos anos, a cultura da contabilidade orçamentária na administração pública vem sendo alterada buscando-se a adoção da contabilidade pública patrimonial. Nesse processo, inicialmente, em 2007, os Princípios de Contabilidade foram interpretados sob a perspectiva do setor público e, posteriormente, em 2008 teve-se a normatização das NBC TSP.

Cabe destacar que, até 2007 , os profissionais que atuam na área pública não possuíam clareza se os Princípios de Contabilidade normatizados pelo CFC deviam ser seguidos também na contabilidade pública. Isso ficou esclarecido com a Resolução do CFC n. 1.111/07, alterada pela Resolução n. 1.367/11, que instituiu o Apêndice II à Resolução 750/93 que tratou dos Princípios de Contabilidade sob a perspectiva do setor público.

Com exceção do princípio da competência, cuja interpretação para o setor público, foi exatamente a mesma do setor privado, todos os demais princípios foram interpretados considerando as particularidades da área governamental. Destaca-se a interpretação dada aos princípios da entidade e da continuidade que abordaram a destinação social do patrimônio e a responsabilização do gestor ao dispor que:

Estudos do CEPE [ISSN 1982-6729]. Santa Cruz do Sul, n. 42, p. 114-131, jul./dez. 2015. https://online.unisc.br/seer/index.php/cepe/index 
O Princípio da Entidade se afirma, para o ente público, pela autonomia e responsabilização do patrimônio a ele pertencente. A autonomia patrimonial tem origem na destinação social do patrimônio e a responsabilização pela obrigatoriedade da prestação de contas pelos agentes públicos. No âmbito da entidade pública, a continuidade está vinculada ao estrito cumprimento da destinação social do seu patrimônio, ou seja, a continuidade da entidade se dá enquanto perdurar sua finalidade (CFC, Resolução CFC n. 1.111/07).

A partir da leitura dos Princípios de Contabilidade sob a perspectiva do setor público, não há mais dúvida quanto à obrigatoriedade da adoção do regime da competência para o registro das transações, inclusive as receitas públicas que até então vinham sendo contabilizadas no patrimônio pelo regime de caixa seguindo o padrão de registro no subsistema de informações orçamentárias.

Outro avanço para a área pública foi a edição das NBC TSP pelo Conselho Federal de Contabilidade (CFC), visando à sua convergência aos padrões internacionais, para o qual foi instituído por meio da Resolução do CFC n. 1.103/2007, um Conselho Gestor de Convergência no Brasil. O processo de convergência da contabilidade pública aos padrões internacionais, segundo Carlin (2008), pode ser caracterizado por quatro ações, a saber: a elaboração, discussão e apresentação de projeto de lei para alteração da Lei n. 4.320/64; a elaboração, discussão e edição das NBC TSP; a tradução das International Public Setor Accounting Standards (IPSAS); e a convergência das NBC TSP às IPSAS até 2012.

Na realização da primeira ação, o CFC criou em 2004 um grupo de trabalho, visando realizar um estudo e apresentar propostas para alteração da referida Lei. O projeto passou por ampla discussão pelo Grupo Gestor das NBC TSP e atualmente encontra-se em tramitação no Poder Legislativo Federal o projeto consolidado da Lei de Qualidade Fiscal que tem como objetivo estabelecer normas gerais de contabilidade e de finanças públicas voltadas para a qualidade da gestão, bem como revogar a Lei n. 4.320/64 e alterar dispositivos da Lei n. 101/00 no sentido de fortalecer a gestão fiscal responsável.

A segunda ação consolidada foi o processo de discussão e edição em novembro de 2008 das NBC TSP com o envolvimento e a colaboração de profissionais da contabilidade de notória especialização, os quais atuaram como relatores e revisores. Por meio da Portaria do MF n. 184/08 ficou determinado à Secretaria do Tesouro Nacional (STN) o desenvolvimento de ações no sentido de promover a convergência com as Normas Internacionais de Contabilidade Pública. Nesse sentido, entre outras ações, visando à aplicação das NBC TSP, a STN vem editando os Manuais de Contabilidade Aplicados ao Setor Público, que apresentam procedimentos orçamentários e patrimoniais específicos, bem como definem um plano de contas e a estrutura das Demonstrações Contábeis.

Com a edição das NBC TSP já se buscou uma convergência parcial aos padrões internacionais das IPSAS publicadas pela International Federation of Accountants (IFAC). Segundo Fragoso et al. (2010), a maior parte das 31 IPSAS editadas pela IFAC foram contempladas nas NBC TSP com maior ou menor percentual de convergência. Entretanto, os autores salientam que "há diversos aspectos a serem discutidos para uma efetiva convergência às normas internacionais" e enfatizou que "esta convergência atual é parcial" (FRAGOSO et al., 2010, p. 1).

Para a realização da terceira ação que consistiu na tradução das IPSAS foi contratada uma empresa especializada. Já a quarta e última ação foi planejada para o ano de 2012 em conformidade

Estudos do CEPE [ISSN 1982-6729]. Santa Cruz do Sul, n. 42, p. 114-131, jul./dez. 2015. https://online.unisc.br/seer/index.php/cepe/index 
com o plano de ação do Comitê Gestor de Convergência no Brasil, que prevê a convergência das NBC TSP às IPSAS. Essa tarefa está sob a liderança do sistema CFC/CRCs e da Secretaria do Tesouro Nacional, conforme determinação da Portaria do MF n. 184/08.

O momento atual é de disseminação das NBC TSP para que essas sejam devidamente implementadas pelos profissionais contábeis, passando o setor público a ter, assim, uma contabilidade patrimonial geradora de informações em lugar de uma contabilidade orçamentária.

\subsection{Principais Alterações e Inovações Trazidas Pelas NBC TSP}

Considerando o objetivo do presente estudo, cabe inicialmente destacar o importante papel das normas de contabilidade aplicadas ao setor público ao processo evolutivo da contabilidade aplicada ao setor público, sendo necessária uma abordagem das principais alterações trazidas pelas NBC TSP, dando, assim, um novo sentido à informação contábil gerada pelo profissional da contabilidade pública.

As NBC TSP abordam desde a conceituação, o objeto e o campo de aplicação da contabilidade até a obrigatoriedade da instituição do sistema de custos, identificadas ainda pela sistemática anterior em algarismos arábicos, como NBC T 16, com 11 divisões especificadas no quadro 01.

\section{Quadro 01 - Descrição das NBC TSP}

\begin{tabular}{|l|l|}
\hline \multicolumn{1}{|c|}{$\begin{array}{c}\text { Número da Norma } \\
\text { (NBC) }\end{array}$} & \multicolumn{1}{c|}{ Descrição } \\
\hline NBC T 16.1 & Conceituação, objeto e campo de aplicação \\
\hline NBC T 16.2 & Patrimônio e sistemas contábeis \\
\hline NBC T 16.3 & Planejamento e seus instrumentos sob o enfoque contábil \\
\hline NBC T 16.4 & Transações no setor público \\
\hline NBC T 16.5 & Registro contábil \\
\hline NBC T 16.6 & Demonstrações contábeis \\
\hline NBC T 16.7 & Consolidação das demonstrações contábeis \\
\hline NBC T 16.8 & Controle interno \\
\hline NBC T 16.9 & Depreciação, amortização e exaustão \\
\hline NBC T 16.10 & $\begin{array}{l}\text { Avaliação e mensuração de ativos e passivos em entidades do setor } \\
\text { público }\end{array}$ \\
\hline NBC T 16.11 & Sistema de Informação de custos do setor público \\
\hline Fonte: CFC, NBC T 16 & \multicolumn{2}{|l}{} \\
\hline
\end{tabular}

A primeira norma, a NBC T 16.1, definiu que o patrimônio e não o orçamento é o objeto da contabilidade pública, deixando definitivamente claro quais são as entidades que estão no campo de atuação da contabilidade pública, o que, até então, não era consenso. Segundo a norma, ficou estabelecido que fazem parte do campo de atuação da contabilidade pública as entidades do setor público, as quais englobam "órgãos, fundos e pessoas jurídicas de direito público ou que, possuindo personalidade jurídica de direito privado, recebam, guardem, movimentem, gerenciem ou apliquem dinheiros, bens e valores públicos, na execução de suas atividades", equiparando-se para efeito contábil "as pessoas físicas que recebam subvenção, benefício, ou incentivo, fiscal ou creditício, de órgão público" (CFC, NBC T 16.1). 
Como principal alteração introduzida pela NBC T 16.2 pode-se destacar a designação dos subsistemas de informação contábil denominados de subsistema orçamentário, patrimonial, custos e compensação. A norma suprimiu o sistema financeiro passando este a fazer parte do subsistema patrimonial. Com isso, os lançamentos contábeis no setor público tornam-se menos complexos e mais compatíveis com a contabilidade de empresas do setor privado.

Segundo a NBC T 16.3, "a contabilidade aplicada ao setor público deve permitir a integração dos planos hierarquicamente interligados, comparando as metas programadas com as realizadas, e evidenciando as diferenças relevantes por meio de notas explicativas". A maior inovação está na ampliação do controle contábil sobre os instrumentos de planejamento - Plano Plurianual (PPA), Lei de Diretrizes Orçamentárias (LDO) e Lei Orçamentária Anual (LOA). Segundo Darós e Pereira (2009), essa norma amplia tal controle, pois além de evidenciar a execução orçamentária anual, pretende-se acompanhar o cumprimento das metas estratégicas contidas no PPA.

Ao dispor sobre as transações no setor público, a NBC T 16.4 trouxe uma classificação para os atos e fatos dividindo-os em econômico-financeiros e administrativos, sendo os primeiros originados por transações que afetam o patrimônio público, dependentes ou independentes da execução orçamentária e os segundos originados de atos administrativos que não afetam o patrimônio público. Além disso, a norma, ao dispor sobre as transações que envolvem valores de terceiros, as chamadas transações extraorçamentárias que não afetam o patrimônio público, reafirmou que as mesmas devem ser demonstradas de forma segregada.

Os registros contábeis para a área pública foram normatizados pela NBC T 16.5, que definiu as características do registro e da informação contábil, a composição do plano de contas, a elaboração dos livros diário e razão, entre outros. Também trouxe disposições sobre a segurança da documentação contábil, bem como critérios de reconhecimento e bases de mensuração ou avaliação aplicáveis ao patrimônio. Em termos de inovação pode-se dizer que a NBC T 16.5 trouxe algumas bases para o registro contábil no setor público que até então não existiam, sendo que os profissionais contábeis nessa área não tinham clareza se deviam adotar as mesmas formalidades da empresa privada. Entre as adequações trazidas pela norma, destaca-se o regime da competência, o qual ficou claramente disposto na norma.

No entendimento de Darós e Pereira (2009, p. 6) o posicionamento da NBC T 16.5 "demonstra um desprendimento do foco estritamente orçamentário, e serve como reforço para a implementação de uma contabilidade pública com visão patrimonial", devendo essa evidenciar a totalidade das transações no setor público de modo que prevaleça a essência da ciência contábil.

A NBC T 16.6 trouxe como principais alterações a mudança na estrutura das demonstrações que já estavam regulamentadas na Lei n. 4.320/64 de forma a torná-las mais informativas. Inovou com a instituição de duas novas demonstrações, a Demonstração do Fluxo de Caixa e a Demonstração do Resultado Econômico. Cabe destacar que a norma definitivamente instituiu que as notas explicativas são parte integrante das demonstrações contábeis, haja vista que até então os Poderes Públicos, mais especificamente os da esfera municipal, não elaboravam notas explicativas para as demonstrações. A norma também reafirmou que as demonstrações devem ser amplamente divulgadas à sociedade.

Estudos do CEPE [ISSN 1982-6729]. Santa Cruz do Sul, n. 42, p. 114-131, jul./dez. 2015. https://online.unisc.br/seer/index.php/cepe/index 
Em relação a consolidação das demonstrações contábeis objetivando o conhecimento e a disponibilização de macroagregados do setor público, a visão global do resultado e a instrumentalização do controle social, a NBC T 16.7 não trouxe inovações à medida que a consolidação já era prevista nos artigos n. 111 da Lei n. 4.320/64 e n. 51 da Lei n. 101/00. Contudo, a norma agregou ao determinar critérios para realizar a consolidação, dispondo que "os ajustes e as eliminações decorrentes do processo de consolidação devem ser realizados em documentos auxiliares, não originando nenhum tipo de lançamento na escrituração das entidades que formam a unidade contábil" (CFC, NBC T 16.7).

Quanto a NBC T 16.8, pode-se verificar como inovação a ampliação da atuação do Controle Interno para as transações de natureza contábil e operacional, visando assim uma efetiva fiscalização dos registros contábeis realizados e das ações de natureza mais administrativa que envolvem todo o fluxo de informações necessário para o funcionamento dos serviços públicos. Até então, o Controle Interno, possuía uma atuação mais normativa (fiscalização do cumprimento de leis) em consonância com o artigo n. 59 da Lei n. 101/00 e de natureza orçamentária (acompanhamento da execução do orçamento) conforme o artigo n. 77 da Lei n. 4.320/64.

A obrigatoriedade do registro da depreciação, amortização e exaustão no Poder Público foi uma das grandes inovações da NBC T 16.9, devendo tal registro ser mensal até que o valor contábil do ativo seja igual ao valor residual.

No que se refere à avaliação e mensuração de ativos e passivos em entidades do setor público, tratada pela NBC T 16.10, pode-se destacar, como adequação, a obrigatoriedade da contabilização dos ativos de infraestrutura, também chamados de bens de uso comum do povo que até então não constavam no ativo imobilizado dos entes públicos. A norma também inovou ao tratar não somente das reavaliações que já eram permitidas na Lei n. 4.320/64, mas também da redução ao valor recuperável (impaiment).

A última norma, a NBC T 16.11, instituída posteriormente, tratou do sistema de informação de custos no setor público abordando desde noções conceituais até os objetivos e regras básicas para implantação do subsistema de custos no setor público. Essa norma não inovou a exigência de sistema de custos no Poder Público, pois já havia determinações na Lei n. 4.320/64 em seu artigo n. 99, e na Lei n. 101/00 em seu artigo n. 50, § 3º. Contudo inovou ao estabelecer regras básicas para nortear a efetiva implementação do sistema de custos.

O prazo para os entes governamentais aderirem às normas, previsto inicialmente para a União e Estados, em 2012, e para os Municípios em 2013, foi ajustado pela Portaria Conjunta STN/SOF n. 01/11, que definiu pela aplicação dos procedimentos contábeis orçamentários e específicos, a partir de 2012, para os três entes da federação. Por sua vez, a Portaria MF n. 828/11 determinou a aplicação dos procedimentos patrimoniais de forma gradual, a partir de 2012, e integralmente até o final do exercício de 2014. A adoção do plano de contas e a elaboração das Demonstrações Contábeis dentro das novas normas deve ocorrer de forma obrigatória a partir de 2013.

Corroborando o entendimento de vários autores, reforça-se que as NBC TSP, editadas em 2008, significam um avanço ao processo de convergência das normas contábeis brasileiras às 
Normas Internacionais de Contabilidade Aplicadas ao Setor Público e identificam o Brasil como uma nação que está caminhando para incorporação e harmonização de padrões uniformes de contabilidade ao setor público.

\section{METODOLOGIA}

Para analisar o processo de adequação dos Municípios da Região Centro Serra - RS às mudanças da contabilidade no contexto da harmonização das normas de contabilidade aplicadas ao setor público, inicialmente realizou-se uma pesquisa bibliográfica buscando identificar as principais mudanças para a contabilidade pública decorrentes da aprovação das Normas Brasileiras de Contabilidade Aplicadas ao Setor Público - NBCASP dentro do processo de convergência às normas internacionais.

Os dados empíricos foram levantados com base na pesquisa de levantamento (survey) por meio da aplicação de um questionário respondido diretamente pelos profissionais contábeis dos municípios da amostra, visando identificar o nível de conhecimento desses profissionais, a aplicação das novas normas e as condições da estrutura organizacional. A aplicação do questionário foi realizada nos meses de janeiro e fevereiro de 2012, ano inicial de implantação das novas normas de forma facultativa, tendo em vista a Portaria STN n. 828/11, que estabeleceu a implantação gradual do novo padrão até 2014, sendo até o final de 2012 de forma facultativa e após, em 2013 a 2014, obrigatoriamente.

Nos municípios do estudo trabalham em média de três a quatro servidores no setor contábil, tendo entre eles apenas um profissional contábil 'contabilista' responsável pela contabilidade, que foi selecionado intencionalmente para responder ao questionário. Salienta-se que a delimitação da unidade de análise, os municípios da Região Centro-Serra - RS, caracterizam uma estratificação que reproduz a realidade enfrentada pela maioria dos pequenos municípios brasileiros, assim entendidos os com até 50.000 habitantes. O parâmetro utilizado para a classificação apresentada, de pequeno município, tem como referência a Lei de Responsabilidade Fiscal que estabelece tratamento diferenciado para algumas exigências aos municípios com até esta população.

A população dos onze municípios integrantes da Região Centro-Serra é de aproximadamente 70.000 habitantes, sendo a grande maioria essencialmente agrícola, com produção de milho, fumo, soja, feijão e também a pecuária leiteira. Destacam-se com empresas e algumas indústrias calçadista, fumageira, madeireira, vinícola e metalúrgica os municípios de Sobradinho e Arroio do Tigre. No Quadro 2 apresenta-se uma breve caracterização desses municípios com informações demográficas, financeiras, e econômicas.

Estudos do CEPE [ISSN 1982-6729]. Santa Cruz do Sul, n. 42, p. 114-131, jul./dez. 2015. 
Quadro 2 - Informações dos municípios que compõem a região Centro-Serra

\begin{tabular}{|l|c|c|c|c|}
\hline \multicolumn{1}{|c|}{ Municípios } & $\begin{array}{c}\text { População } \\
\text { (Habitantes) } \\
\mathbf{2 0 1 1}\end{array}$ & $\begin{array}{c}\text { Receita } \\
\text { Arrecadada } \\
\mathbf{2 0 1 1}\end{array}$ & $\begin{array}{c}\text { PIB Município } \\
\text { 2009 (R\$) }\end{array}$ & $\begin{array}{c}\text { PIB per capita } \\
\text { 2009 (R\$) }\end{array}$ \\
\hline Jacuizinho & 2.619 & $8.656 .110,87$ & 44.878 & 16.231 \\
\hline Estrela Velha & 3.628 & $13.683 .754,20$ & 74.812 & 19.807 \\
\hline Arroio do Tigre & 12.648 & $19.919 .732,94$ & 208.363 & 15.776 \\
\hline Ibarama & 4.371 & $11.301 .336,15$ & 53.799 & 12.109 \\
\hline Sobradinho & 14.285 & $26.071 .243,35$ & 170.511 & 11.565 \\
\hline Passa Sete & 5.159 & $13.052 .629,15$ & 65.306 & 12.369 \\
\hline Cerro Branco & 6.404 & $12.811 .132,53$ & 54.877 & 11.743 \\
\hline Tunas & 4.395 & $10.744 .248,02$ & 48.574 & 10.673 \\
\hline Lagoão & 6.185 & $10.591 .496,16$ & 59.938 & 8.943 \\
\hline Lagoa Bonita do Sul & 2.617 & $7.504 .535,50$ & 40.240 & 14.585 \\
\hline Segredo & 7.158 & $15.661 .513,17$ & 83.060 & 11.377 \\
\hline
\end{tabular}

Fonte: Fundação de Economia e Estatística - FEE, 2011

Visando a uma melhor compreensão da delimitação da unidade de análise, os municípios integrantes da Região Centro-Serra, cabe mencionar a divisão do território do estado gaúcho, agrupado por municípios com características semelhantes, sendo elas geográficas, culturais e econômicas. O objetivo dessa divisão foi o de promover o desenvolvimento regional e harmônico, assim como a integração dos recursos e das ações do governo em cada região, intituída por meio da Lei n. 10.283/94 que criou os Conselhos Regionais de Desenvolvimento (COREDES). Atualmente o estado do Rio Grande do Sul possui 28 Conselhos, do qual faz parte a Região Centro-Serra, formada por 11 municípios de pequeno porte.

Pelas variáveis estudadas, a presente pesquisa é descritiva e em termos de abordagem, se enquadra como qualitativa-quantitativa. Sua classificação como descritiva refere-se ao levantamento, descrição e análise das características sobre a preparação dos profissionais contábeis e da estrutura organizacional dos municípios da Região Centro-Serra, em relação ao processo de adequação às novas normas de contabilidade aplicadas ao setor público.

Utilizou-se da abordagem qualitativa à medida que foi realizada a descrição e análise do processo de adaptação dos Municípios da Região Centro-Serra do Estado do Rio Grande do Sul RS em relação às mudanças da contabilidade aplicada ao setor público. A utilização da abordagem quantitativa se caracterizou pelo emprego da quantificação dos dados e da técnica de análise em percentuais, proporcionando uma visão geral do processo de adequação dos Municípios às mudanças da contabilidade aplicada ao setor público.

\section{DESCRIÇÃO E ANÁLISE DOS DADOS E RESULTADOS}

Visando verificar o processo de adequação dos municípios às novas normas de contabilidade aplicadas ao setor público, dividiu-se a análise em três momentos. Inicialmente, buscou-se identificar o nível de conhecimento dos profissionais da área contábil sobre o entendimento dos Princípios de Contabilidade sob a perspectiva do setor público e das NBC TSP,

Estudos do CEPE [ISSN 1982-6729]. Santa Cruz do Sul, n. 42, p. 114-131, jul./dez. 2015. https://online.unisc.br/seer/index.php/cepe/index 
especificamente as NBC T161 a 16.11. No segundo momento, buscou-se verificar se as normas já estão sendo aplicadas e quais as principais dificuldades enfrentadas. Por último investigou-se a adequação da estrutura organizacional dos municípios para aplicação das novas normas de contabilidade.

\subsection{Nível de Conhecimento dos PC sob a Perspectiva do Setor Público e das NBC TSP}

A partir da amostra dos 11 municípios da Região Centro-Serra, constatou-se que a grande maioria dos profissionais contabilistas, 91\%, são sabedores da existência dos princípios de contabilidade, bem como das NBC TSP. Questionados se já estudaram as duas normatizações, observou-se que a maioria dos profissionais, 55\%, não estudaram os PC. Em relação às Normas constatou-se que um número significativo já estudou em parte as NBC T 16, conforme detalhado no Quadro 3. Constatou-se, por parte dos contabilistas, que o acesso ao conteúdo das NBC TSP se deu por meio dos Manuais de contabilidade aplicados ao setor público, elaborados pela STN dentro das suas ações no processo de convergência.

Quadro 3 - Leitura dos PC e das NBC TSP

\begin{tabular}{|c|c|c|c|}
\hline \multirow{2}{*}{ Questionamentos } & \multicolumn{3}{|c|}{ Respostas } \\
\hline & Sim & Em parte & Não \\
\hline $\begin{array}{l}\text { Leitura e análise da Resolução do CFC 750/93 e do } \\
\text { referido Apêndice }\end{array}$ & $09 \%$ & $36 \%$ & $55 \%$ \\
\hline Leitura e análise das NBC TSP & $09 \%$ & $73 \%$ & $18 \%$ \\
\hline
\end{tabular}

O levantamento também buscou uma autoavaliação dos profissionais quanto a seus conhecimentos e nível de entendimento sobre os PCs e as novas normas. A maioria dos profissionais consideraram ter um nível regular de conhecimento e entendimento sobre os PCs e as NBC TSP, conforme resultados apurados no Quadro 4.

Quadro 4- Nível de conhecimento e entendimento dos profissionais

\begin{tabular}{|l|c|c|c|c|}
\hline \multicolumn{2}{|c|}{ Questionamentos } & \multicolumn{4}{c|}{ Respostas } \\
\cline { 2 - 5 } & Muito bom & Bom & Regular & Não possui \\
\hline Nível de entendimento dos PC & $0 \%$ & $27 \%$ & $64 \%$ & $9 \%$ \\
\hline Nível de entendimento das NBCASP & $0 \%$ & $18 \%$ & $73 \%$ & $9 \%$ \\
\hline
\end{tabular}

Fonte: Dados da pesquisa

Em relação ao nível de conhecimento dos profissionais é relevante destacar que, dos onze contabilistas, nove responderam que seus conhecimentos se devem à participação em cursos com a Delegação de Prefeituras Municipais - DPM - com sede na capital Porto Alegre, que, além de oferecer cursos diretamente para área pública, presta assessorias contábeis, jurídicas, pessoal e também tributária. Essa entidade possui comprometimento em manter os municípios atualizados com as constantes mudanças que vêm ocorrendo neste setor.

As principais mudanças apontadas pelos contabilistas, em relação aos PCs e às NBC TSP, referem-se ao enfoque patrimonial e ao registro pelo regime de competência, o que evidencia que os profissionais estão a par da essência das mudanças introduzidas pelas novas normas, apesar de a 
maioria dos profissionais entrevistados ter julgado seu nível de conhecimento e entendimento como regular.

Com base nas análises realizadas constatou-se em relação ao preparo dos profissionais da área contábil, que esse preparo está em estágio inicial, tendo os profissionais conhecimento da existência dos Princípios de Contabilidade sob a perspectiva da área pública e sobre a NBC T 16. No entanto, poucos a estudaram de uma forma integral, tendo agregado conhecimento por meio de treinamentos realizados. Nota-se a necessidade de um aprofundamento do conhecimento e do entendimento por parte dos profissionais de forma que os PCs e as NBC TSP sejam efetivamente aplicados no dia a dia da contabilidade pública, mudando a cultura contábil orçamentária para patrimonial.

\subsection{Aplicação da NBC TSP Pelos Profissionais}

No levantamento da aplicação das novas normas pelos profissionais da contabilidade do setor público, buscou-se primeiramente investigar o nível de dificuldade de implantação e as contribuições para a melhoria da qualidade das informações produzidas pela contabilidade. Após verificou-se como está a aderência da implantação das normas, tendo em vista que, conforme a Portaria STN n. 828/11, o novo padrão deve ser implantado de forma gradual até 2014, conforme cronograma elaborado pelos diferentes municípios.

Em relação ao nível de dificuldade na implantação das novas normas, os contabilistas das prefeituras do estudo relataram que existem muitas situações que dificultam a implementação das novas normas pelos profissionais da área contábil, citando a carência de profissionais capacitados, a falta de designação de atribuições aos servidores e a respectiva cobrança. Na opinião de $73 \%$ dos profissionais os novos procedimentos melhorarão muito a qualidade das informações produzidas pela contabilidade.

Quanto à aplicação das normas, apresenta-se no Quadro 5 um mapeamento da situação levantada, no qual identificam-se dados referentes à aplicação ou não das normas e à existência de iniciativas do município visando a sua aplicação.

Quadro 5 - Aplicação das novas normas pelos profissionais da área
\begin{tabular}{|l|c|c|c|}
\hline Procedimentos da Portaria 828/11 & $\begin{array}{c}\text { Sendo } \\
\text { aplicad } \\
\text { o }\end{array}$ & $\begin{array}{c}\text { Não } \\
\text { aplicad } \\
\text { o }\end{array}$ & $\begin{array}{c}\text { Existem } \\
\text { iniciativa } \\
\text { S }\end{array}$ \\
\hline $\begin{array}{l}\text { Reconhecimento, mensuração e evidenciação dos créditos, } \\
\text { tributários ou não, por competência, bem como da dívida ativa, } \\
\text { incluindo os respectivos ajustes para perdas. }\end{array}$ & $36 \%$ & $64 \%$ & 0 \\
\hline $\begin{array}{l}\text { Reconhecimento, mensuração e evidenciação das obrigações e } \\
\text { provisões por competência. }\end{array}$ & $27 \%$ & $55 \%$ & $18 \%$ \\
\hline $\begin{array}{l}\text { Reconhecimento, mensuração e evidenciação dos bens móveis, } \\
\text { imóveis e intangíveis. }\end{array}$ & $55 \%$ & $18 \%$ & $27 \%$ \\
\hline $\begin{array}{l}\text { Registro de fenômenos econômicos, resultantes ou } \\
\text { independentes da execução orçamentária, tais como } \\
\text { depreciação, amortização, exaustão. }\end{array}$ & $09 \%$ & $64 \%$ & $27 \%$ \\
\hline $\begin{array}{l}\text { Reconhecimento, mensuração e evidenciação dos ativos de } \\
\text { infraestrutura considerados bens de uso comum do povo. }\end{array}$ & $09 \%$ & $91 \%$ & 0 \\
\hline Implementação do sistema de custos. & $09 \%$ & $73 \%$ & $18 \%$ \\
\hline $\begin{array}{l}\text { Aplicação do Plano de Contas, detalhado no nível exigido para a } \\
\text { consolidação das contas nacionais }\end{array}$ & $64 \%$ & $18 \%$ & $18 \%$ \\
\hline
\end{tabular}

Fonte: Dados da pesquisa
Estudos do CEPE [ISSN 1982-6729]. Santa Cruz do Sul, n. 42, p. 114-131, jul./dez. 2015. https://online.unisc.br/seer/index.php/cepe/index 
Os resultados obtidos evidenciaram que 55\% dos municípios ainda não iniciaram a elaboração do cronograma e as demais providências para o atendimento dos procedimentos contábeis patrimoniais e específicos estipulados pela Portaria MF n. 828/11. No que se refere a cada um dos procedimentos específicos a serem implementados, nota-se que, com exceção do reconhecimento, mensuração e evidenciação dos bens móveis e intangíveis e a aplicação do Plano de Contas, os demais procedimentos ainda não estão sendo implementados pela maior parte dos municípios, existindo poucas iniciativas para a adequação dos municípios ao novo padrão de contabilidade.

Destaca-se com relação á aplicação da competência integral, a qual é uma das principais mudanças introduzidas para a contabilidade aplicada ao setor público, que somente quatro municípios estão aplicando o novo procedimento no que se refere ao reconhecimento dos créditos e três no que se refere às obrigações e provisões. A depreciação, a evidenciação dos ativos de infraestrutura considerados bens de uso comum do povo e a implementação do sistema de custos estão sendo aplicados apenas por um município, conforme dados informados.

Em relação às principais alterações introduzidas na contabilidade pública, buscou-se também a opinião dos profissionais sobre as melhorias para a informação produzida pela contabilidade, bem como sobre a implementação dessas mudanças. Para tanto, foram realizados questionamentos sobre oito alterações, obtendo-se os entendimentos por parte dos profissionais, detalhados na sequência.

A primeira alteração elencada foi a instituição do sistema contábil subdividido em quatro subsistemas de informações: orçamentário, compensado, patrimonial e custos, deixando de existir o sistema financeiro, o qual passou a fazer parte do subsistema patrimonial. Segundo o entendimento de alguns profissionais, somente após a implantação poderão ser visualizados os benefícios. Já outros afirmaram que observando o novo sistema comparado à forma atual, é possível verificar que, com a supressão do sistema financeiro e o registro das informações diretamente no subsistema de informações patrimoniais, as informações ficarão mais objetivas, o que é relevante ao andamento dos projetos e atividades.

Na sequência os profissionais foram questionados em relação à implantação do sistema de custos, cuja matéria está expressa nas Leis n. 4.320/64 e 101/00. Como resposta foram relatados, pelos profissionais, várias dificuldades para a implementação, porém concordam com os efeitos positivos dessa implementação, possibilitando melhor controle dos custos aplicados em determinados setores e órgãos, bem como a racionalização dos gastos públicos.

Quanto ao sistema de planejamento estratégico, voltado à contabilidade pública, por meio de uma maior integração entre os planos PPA, LDO e LOA, com a inclusão da contabilização do PPA, o que permite uma melhor comparação das metas projetadas com as executadas no orçamento anual, os profissionais entendem que existem muitos empecilhos para isso se concretizar, como por exemplo o acompanhamento e a execução de metas inadequadamente projetadas. Para alguns, a integração entre os planos já existe, mas entendem que é ineficaz.

A contabilização pelo regime de competência, principalmente no que se refere à receita, contabilizada no setor público pelo regime de caixa, foi apontada por alguns profissionais, como 
sendo de difícil implantação, tendo em vista a necessidade da identificação do fato gerador. Alguns profissionais afirmaram também que já utilizam o regime de competência, tendo outros, relatado que haverá algum desconforto até ser assimilado o processo.

Questionados sobre a contabilização dos bens de uso comum do povo que consumiu ou consome recursos públicos, de forma geral os profissionais contábeis responderam que será o procedimento mais difícil de realizar, tendo dúvidas quanto ao seu registro e à sua mensuração.

No que se refere à depreciação, que passou a ser procedimento obrigatório para a contabilidade pública, os profissionais, reconhecem com unanimidade a relevante necessidade de implementação na área pública. Enfatizam que os sistemas informatizados ainda estão se aprimorando para o devido lançamento e prometem atender a este procedimento com a prorrogação de prazo que foi estabelecida, ressaltando que o inventário e a reavaliação são procedimentos patrimoniais que já estão sendo realizados em alguns municípios.

Sobre a inclusão das novas demonstrações contábeis incluídas pela NBC TSP no rol das Demonstrações Contábeis, respectivamente a Demonstração do Fluxo de Caixa e Demonstração do Resultado Econômico, a opinião dos contabilistas é que as mesmas, além de mais trabalho e responsabilidade, possibilitarão mais informações com foco gerencial, enfatizando a situação econômico-financeira da entidade.

Exigência desde a Lei n. 4320/64, o controle interno tem mais uma regulamentação com as NBC TSP, potencializando o amplo campo de atuação desses controles como suporte do sistema de informação contábil. Questionados sobre melhoria dos controles internos a partir da normatização pela NBC T 16.8, a maioria dos contabilistas afirmou que só a normatização não é suficiente. Os gestores (prefeitos) precisam conscientizar-se da importância do papel do controle interno, por meio da efetivação de cargos para atuar especificamente nessa função, buscando a eficiência desses profissionais com treinamentos, para assim, tê-los como colaboradores numa gestão mais transparente e eficaz.

A grande dificuldade na implementação e assimilação desses procedimentos é a carência de profissionais da área e também nas demais áreas que participam do fluxo das informações contábeis. A maioria dos respondentes destacou o singelo conhecimento dos profissionais em relação a esse processo de adequação. Em contraste, registraram a enorme preocupação em adequar-se. Salientaram que essas mudanças trazem de forma positiva, agregada às informações gerenciais, mais transparência, responsabilização e controle, auxiliando no cumprimento de dispositivos da Constituição, da Lei n. 4320/64 e da Lei de Responsabilidade Fiscal.

\subsection{Adequação da Estrutura Organizacional dos Municípios}

A aplicação das novas normas de contabilidade requer que o município trabalhe com sistemas informatizados integrados (contabilidade, tesouraria, folha de pagamento, patrimônio, almoxarifado, compras e licitação). Nesse sentido buscou-se averiguar essa integração, no qual verificou-se que a maior parte dos municípios, $64 \%$, possui seus sistemas parcialmente integrados e apenas $27 \%$ estão com seus sistemas totalmente integrados, conforme evidenciado no quadro 6.

Estudos do CEPE [ISSN 1982-6729]. Santa Cruz do Sul, n. 42, p. 114-131, jul./dez. 2015. https://online.unisc.br/seer/index.php/cepe/index 
Também é necessário, ao atendimento das novas normas de contabilidade, que os municípios estejam com seus setores organizados, garantindo um bom fluxo de informações para a escrituração contábil. O profissional contábil somente poderá registrar a receita pelo regime de competência e apropriar as provisões de décimo terceiro e férias, por exemplo, se os setores de arrecadação e pessoal produzirem adequadamente as informações. O mesmo acontece com o registro dos bens de uso comum do povo e da depreciação que somente podem ser realizados pelo profissional contábil se o município tiver um setor de controle patrimonial organizado.

Entre os profissionais contábeis, 55\% avaliaram os setores parcialmente organizados, 36\% como não integrados e apenas $9 \%$ como totalmente organizados. No fluxo de informações e organização dos setores interligados com a contabilidade, nota-se uma deficiência acentuada para que os profissionais da área contábil possam conduzir o processo de adequação às novas normas de contabilidade aplicadas ao setor público.

\section{Quadro 6- Adequação da estrutura organizacional para a aplicação das novas normas}

\begin{tabular}{|l|c|c|c|c|}
\hline \multirow{2}{*}{ Questionamentos } & \multicolumn{4}{|c|}{ Nível de integração/organização } \\
\cline { 2 - 5 } & Totalmente & Parcialmente & $\begin{array}{c}\text { Buscando } \\
\text { integração/ } \\
\text { organização }\end{array}$ & $\begin{array}{c}\text { Não } \\
\text { integrados/ } \\
\text { organizados }\end{array}$ \\
\hline Integração dos sistemas & $27 \%$ & $64 \%$ & $9 \%$ & 0 \\
\hline Organização dos setores & $9 \%$ & $55 \%$ & 0 & $36 \%$ \\
\hline
\end{tabular}

Fonte: Dados da pesquisa com base no questionário aplicado

O estudo evidenciou a precariedade dos sistemas informatizados em face da integração, no qual os contabilistas ressaltaram a carência de profissionais capacitados frente à organização dos setores, enfatizando também a preocupação com a implementação dos novos procedimentos.

Questionados ainda sobre a implantação das novas normas de forma facultativa até 2012 e obrigatoriamente em 2013 a 2014, conforme prazos estabelecidos pela STN, 64\% dos profissionais contábeis declararam que, mesmo com a integração dos sistemas informatizados e melhorias da produção de informações por outros setores, a carga de trabalho aumentará em função das novas operações que passam a ser contabilizadas e dos relatórios contábeis que deverão ser elaborados. Por outro lado, esse processo abre novas oportunidades de trabalho para os profissionais contábeis que desejam atuar na área pública.

Para a efetiva implementação das novas normas de contabilidade, importante se faz enfatizar o papel dos Tribunais de Contas - TCs e dos Conselhos Regionais de Contabilidade - CRCs. Os TCs representam muito mais do que a fiscalização e o controle da administração orçamentária, financeira e patrimonial. Estão estritamente relacionados à aplicabilidade da contabilidade pública, da mesma forma que os Conselhos de Contabilidade responsáveis por fiscalizar, orientar e normatizar o exercício da profissão contábil e editar as Resoluções e Normas norteadoras da contabilidade.

\section{CONCLUSÕES}

O presente estudo possibilitou verificar e analisar o processo de adequação de pequenos municípios localizados na Região Centro Serra - RS às mudanças e inovações para a contabilidade pública, decorrentes da aprovação das NBC TSP, sob o ponto de vista do nível de conhecimento e de 
preparação dos profissionais contábeis, da aplicação dos princípios e normas, bem como da adequação da estrutura organizacional.

Os profissionais contábeis das prefeituras analisadas, em sua maior parte, têm conhecimento dos princípios e das normas e identificaram como principais alterações o enfoque patrimonial dado à contabilidade, enfatizando a adoção do princípio da competência para o registro das transações ocorridas no patrimônio público. Contudo, numa autoavaliação, julgam seu conhecimento sobre as alterações em nível regular, desconhecendo a complexidade das alterações que as NBC TSP trarão à contabilidade no setor público.

$\mathrm{Na}$ análise da aplicação dos procedimentos contábeis patrimoniais dentro das novas regras, verificou-se, no levantamento, que em sua maior parte não estão sendo realizados e possuem poucas iniciativas para a sua realização, apesar de os profissionais contábeis reconhecerem a importância da adoção dos novos procedimentos para a melhoria da qualidade da informação produzida pela contabilidade e demonstrarem uma grande preocupação em realizar a adequação. Apontaram, como principal dificuldade para a implementação das novas regras, a carência de profissionais na área contábil, bem como nas demais áreas que participam do fluxo de informações da contabilidade.

Em relação à estrutura organizacional dos pequenos municípios, ficou evidenciada a precariedade dos sistemas informatizados e do fluxo de informações dos setores que geram informações para a contabilidade, como um empecilho para a aplicação das novas normas. Também ficou evidenciada a necessidade da ampliação no quadro de servidores de profissionais contábeis, uma vez que a carga de trabalho aumentará.

Reforça-se que as NBC TSP representam um grande avanço para a contabilidade pública no Brasil. Entretanto, a mudança de uma contabilidade essencialmente orçamentária para uma contabilidade patrimonial representa um grande desafio a ser superado, principalmente, nos pequenos municípios, haja vista as dificuldades levantadas no presente estudo. Essa mudança vai exigir, por parte dos municípios da Região Centro-Serra - RS, uma atenção especial para a capacitação dos profissionais contábeis, para a integração dos sistemas informatizados e para a melhoria do fluxo de informações nos setores ligados a contabilidade.

Nesse processo, cabe ainda salientar a atuação dos Conselhos Regionais de Contabilidade e dos Tribunais de Contas, tanto na realização de ações fiscalizatórias da efetiva adequação dos municípios às NBC TSP, como na realização de cursos, treinamentos e palestras, propiciando uma educação continuada.

\section{REFERÊNCIAS}

BRASIL. Lei 4.320 (1964). Estatui normas Gerais de direito financeiro para elaboração e controle dos orçamentos e balanços da União, Estados, Municípios e do Distrito Federal. Publicada pelo Congresso Nacional em 17 de março de 1964. Disponível em: <http/www.planalto.gov.br/ccivil_03/leis/L4320, htm>. Acesso em: 01 set. 2011.

. Lei Complementar 101 (2000). Estabelece normas de finanças públicas voltadas para a responsabilidade na gestão fiscal e dá outras providências. Publicada em 04 de maio de 2000. 
Disponível em: <http://www.planalto.gov.br/ccivil_03/leis/LCP/Lcp101.htm>. Acesso em 27 de março de 2012.

Portaria MF n. 184, de 25 de agosto de 2008. Dispõe sobre as diretrizes a serem observadas no setor público (pelos entes públicos) quando aos procedimentos, práticas, elaboração e divulgação das demonstrações contábeis, de forma a torná-los convergentes com as Normas Internacionais de Contabilidade Aplicadas ao Setor Público. Disponível em:

<http://www.fazenda.gov.br/portugues/legislacao/portarias/2008/portaria184.asp>. Acesso em: 21 mar. 2012.

. Portaria MF n. 828/11. Altera o prazo de implementação do Plano de Contas Aplicado ao Setor Público e dá outras providências. Secretaria do Tesouro Nacional (STN). Disponível em: <http://www.tesouro.fazenda.gov.br/legislacao/download/contabilidade/ PortSTN_828_20111214.pdf>. Acesso em: 10.jan. 2012.

CARLIN, Diego de Oliveira . Considerações sobre o processo de convergência da contabilidade pública brasileira. Revista Eletrônica do CRCRS, Porto Alegre v. 8, p. 1-7, 2008.

CONSELHO FEDERAL DE CONTABILIDADE (CFC). Normas Brasileiras de Contabilidade Aplicadas ao Setor Público (NBC T 16.1 a 16.11). CFC, Brasília. Disponível em :

<http://www.cfc.org.br/sisweb/sre/Confirmacao.aspx>. Acesso em: 10 fev. 2012.

- Resolução do CFC n. 1.103/07. Cria o Comitê Gestor da Convergência no Brasil, e dá outras providências.CFC, Brasília. Disponível em:

<http://www.cfc.org.br/sisweb/sre/detalhes_sre.aspx?Codigo=2007/001103>. Acesso em: 10 fev. 2012.

Resolução do CFC n. 1.111/07 (redação alterada pela Resolução CFC n. 1.367/2011). Aprova o Apêndice Il da Resolução CFC n. 750/93 sobre os Princípios de Contabilidade. Disponível em: <http://www.cfc.org.br/sisweb/sre/detalhes_sre.aspx?Codigo=2007/001111>. Acesso em: 10 fev. 2012.

DARÓS, Leandro Luis; PEREIRA, Adriano de Souza. Análise das normas brasileiras de contabilidade aplicadas ao setor público - NBCASP: mudanças e desafios para a contabilidade pública. In: CONGRESSO USP CONTROLADORIA E CONTABILIDADE, 9. 2009, São Paulo. Anais...São Paulo: USP, 2009. Disponível em: <http://www.congressousp.fipecafi.org/artigos92009. Acesso em: 28 set. 2011.

FEIJÓ, Paulo Henrique. A Importância da Uniformização dos Procedimentos e relatórios contábeis no Brasil. In: SEMINÁRIO INTERNACIONAL DE CONTABILIDADE PÚBLICA, 1., 2007, Brasília. Anais... Brasília: CFC, 2007. p 118-123.

FRAGOSO, Adriana Rodrigues et al. Normas brasileiras e internacionais de Contabilidade aplicadas ao setor público e o desafio da convergência: uma análise comparativa IPSAS e NBCTSP. In: CONGRESSO USP DE CONTROLADORIA E CONTABILIDADE, 10. 2010, São Paulo. Anais... São Paulo: USP, 2010. Disponível em: <http://www.congressousp.fipecafi.org/artigos102010/92.pdf>. Acesso em: 24 mar. 2012.

FUNDAÇÃO DE ECONOMIA E ESTATÍSTICA - FEE. Estatísticas FEE. Disponível em: <http://www.fee.tche.br/sitefee/pt/content/estatisticas/index.php>. Acesso em: 10 fev. 2012.

RIO GRANDE DO SUL - RS. Lei n. 10.283/94. Criou os Conselhos Regionais de Desenvolvimento CRDs. Disponível em: <http://www.scp.rs.gov.br/atlas/atlas.asp?menu>.

ROSA, Maria Berenice. Contabilidade do setor público: de acordo com as inovações das normas brasileiras de contabilidade técnicas aplicadas ao setor público. São Paulo: Atlas, 2011. 
SECRETARIA DO TESOURO NACIONAL. Manual de Contabilidade aplicado ao setor Público: aplicado à União, aos Estados, Distrito Federal e aos Municípios. v I, II, III e IV, 4. ed. Brasília: STN Coordenação geral de contabilidade, 2011.

Estudos do CEPE [ISSN 1982-6729]. Santa Cruz do Sul, n. 42, p. 114-131, jul./dez. 2015. https://online.unisc.br/seer/index.php/cepe/index 